\title{
Salud, inmigración y ayuda mutua en Argentina: el Centro Gallego de Buenos Aires entre la crisis y la emergencia de un nuevo sistema sanitario (1930-1950)
}

\author{
por \\ María Liliana Da Orden ${ }^{1}$ \\ Universidad Nacional de Mar del Plata
}

\begin{abstract}
Este artículo pone en diálogo la historiografía de las migraciones europeas a la Argentina con las investigaciones de historia de la salud a través del análisis del caso del Centro Gallego de la ciudad de Buenos Aires, la sociedad mutual y étnica de mayor relevancia en el país desde los años treinta del siglo pasado. Utilizando fuentes cuantitativas y cualitativas de archivos públicos y privados, se analizan las características de los servicios sanitarios brindados por la institución, la acción de sus dirigentes en la gestión del área, así como la composición de los socios y sus demandas en salud. Los resultados llevan a reconsiderar el papel del sistema mutualista en la época de expansión del sistema público de salud, así como el rol que tuvo la etnicidad en los sectores medios y populares urbanos todavía signados por el origen migratorio mucho después de la oleada de masas.
\end{abstract}

PALABRAS ClaVE: Socorro mutuo; salud; migración gallega; migración española; Argentina; siglo $X X$.

Cómo Citar este artículo / Citation: Da Orden, María Liliana, "Salud, inmigración y ayuda mutua en Argentina: el Centro Gallego de Buenos Aires entre la crisis y la emergencia de un nuevo sistema sanitario (1930-1950)", Revista de Indias, LXXX/280 (Madrid, 2020): 847-880. https://doi.org/10.3989/revindias.2020.024.

Como ha demostrado la historiografía de las migraciones, en la Argentina de las primeras décadas del siglo XX ningún movimiento asociativo podía compararse con la capacidad de convocatoria de las numerosas sociedades de socorros mutuos distribuidas en su vasto territorio. Tanto en las grandes ciu-

1 mldaor9@gmail.com, ORCID iD: https://orcid.org/0000-0003-4652-7062

Copyright: (C) 2020 CSIC. Este es un artículo de acceso abierto distribuido bajo los términos de una licencia de uso y distribución Creative Commons Reconocimiento 4.0 Internacional (CC BY 4.0). 
dades como en los núcleos urbanos medianos o pequeños los distintos colectivos migratorios organizaron entidades de ayuda mutua, casi tantas como los países de origen de donde procedían sus habitantes o incluso más si es que los enfrentamientos internos las dividían o también se había fundado alguna sociedad «cosmopolita». A partir de su estudio se ha podido avanzar en el análisis del importante papel que desempeñó la etnicidad en la sociedad argentina del período. Contrariamente a los postulados del «crisol de razas», tanto el análisis de la composición societaria como la conformación de sus liderazgos pusieron de manifiesto la vigencia de un pluralismo cultural y social de base étnica que claramente confrontaba con la visión que sostenía la rápida asimilación en una sociedad homogénea ${ }^{2}$. Si la contribución de estos estudios es remarcable, el interés por las sociedades de socorros mutuos no avanzó sobre el importante rol que desempeñaron en el cuidado de la salud, al fin y al cabo, uno de sus principales objetivos. Solo en los últimos años se ha planteado la necesidad de atender al «momento mutualista» desde la perspectiva de la importante función sanitaria y previsional que cumplieron ${ }^{3}$. Se abrió así un campo que pone en diálogo los estudios migratorios con los aportes realizados por la historiografía de la salud desarrollada en el país desde las últimas décadas del siglo pasado.

Desde este nuevo ángulo, pues, las investigaciones sobre la inmigración masiva aún tienen mucho que aportar. No obstante, aquí quiero centrarme en un período posterior a partir del estudio del Centro Gallego de Buenos Aires, la sociedad mutual y étnica más importante del país desde mediados de los años treinta del siglo pasado. El caso plantea una doble interpelación, por un lado, se trata de una época en la que, luego haber sufrido una drástica disminución, la afluencia de inmigrantes españoles y de otros orígenes solo fue brevemente retomada con la oleada de posguerra a fines de los años cuarenta. Para entonces, sin embargo, la sociedad se habría tornado más homogénea o «argentinizada» tanto por el aumento de la población nativa como por la acción integradora de las instituciones estatales, los medios de comunicación masiva y las distintas organizaciones sociales ${ }^{4}$, de manera que la etnicidad ya no sería una dimensión relevante. El otro aspecto en cuestión es el lugar del socorro

2 En los años ochenta del siglo pasado el historiador norteamericano Samuel Baily señaló el camino de tales estudios no solo por su funcionamiento sino también por el fructífero aporte que podían realizar al conocimiento de la inserción de los inmigrantes en la nueva sociedad. Baily, 1982. Devoto, 1985; 2003. Devoto y Fernández, 1990. Fernández, 1987. Moya, 2004: 290-348.

3 González Bernaldo de Quirós, 2013.

4 Devoto, 2002. 
mutuo en el sistema de salud. Aquí habían sido decisivos el agotamiento del régimen denunciado en los años treinta, cuando los gobiernos conservadores intervinieron en tantas otras dimensiones, la injerencia del Estado propiciada por los gobiernos que surgieron tras el golpe que los derrocó en 1943 y, particularmente, la llegada de Juan Domingo Perón a la presidencia. Desde 1946 la política sanitaria del peronismo, uno de los mayores logros que esgrimió, habría reemplazado la función que otrora desempeñaran las entidades particulares. Los estudios de la salud han señalado además el impulso dado a las organizaciones mutuales de los sindicatos, denominadas ahora obras sociales, de acuerdo con el creciente papel asignado a los trabajadores por el nuevo gobierno. En el marco de las transformaciones ocurridas en la tercera y cuarta décadas del siglo XX, la integración y la emergencia de un nuevo sistema de salud ocluyeron el rol que desempeñaran las sociedades de socorro establecidas por los inmigrantes. Sin embargo, si este rumbo se visualiza con claridad en la segunda mitad de la centuria pasada, ¿hasta qué punto la fuerte presencia estatal y sindical de los años sesenta y setenta no ha incidido en estas apreciaciones? ¿En qué medida se ha soslayado la especificidad de este período en aras de los cambios que se impondrían más adelante?

Ciertamente los análisis desde el campo de la salud han tenido un mayor desarrollo en este sentido. En un contexto de avance del neoliberalismo, el colapso del sistema sanitario de fines del siglo pasado centró el interés en el rastreo de los orígenes de esta situación. La crisis del movimiento mutualista en los años del treinta y cuarenta fue considerada uno de los indicadores que daban cuenta de la necesidad de un nuevo sistema. Sin embargo, a un régimen fragmentado donde la escasa presencia estatal hacía coexistir la beneficencia con la ayuda mutua, le iba a suceder otro donde el Estado asumió un papel rector singular, habida cuenta del lugar asignado a los sindicatos y sus obras sociales $^{5}$. Si las sociedades de socorro por oficio fueron el antecedente de estas entidades $^{6}$, la crisis financiera y organizativa que acusaba el conjunto de ese movimiento oscureció el papel de otras entidades. Aunque la historiografía de las migraciones avanzó mucho menos sobre este período, la dispar afluencia de la época de posguerra frente a la etapa masiva y la «argentinización», claramente observable en el descenso de la población extranjera, habrían convergido para producir un efecto análogo.

De este modo, poco se sabe de las entidades de ayuda mutua de base étnica, tan variadas por su tipo y escala, así como por los tiempos de su desa-

\footnotetext{
5 Belmartino, 2005.

6 Belmartino et al., 1991: 99-103. Belmartino, 2005: 73-80.
} 
rrollo en un territorio donde la inmigración tuvo un impacto muy desigual ${ }^{7}$. En este trabajo, entonces, busco poner en diálogo la historiografía de las migraciones europeas a la Argentina con las investigaciones de la historia de la salud a través del análisis del caso del Centro Gallego de la ciudad de Buenos Aires, una entidad mutual y étnica cuya expansión fue a contrapelo tanto de las oleadas migratorias como de las tendencias sanitarias del período. ¿Cuáles fueron las razones de este crecimiento? ¿En qué medida las prestaciones diferenciales del centro estaban en la base de la demanda que suscitaba?, ¿qué papel desempeñaba en ella el pluralismo social y cultural vigente durante la inmigración masiva? Para aproximarnos a estas cuestiones analizaré en primer lugar las características de los servicios de este centro en relación con los ofrecidos por distintas instituciones públicas de salud de la ciudad, para considerar seguidamente el papel que al respecto desempeñaron sus dirigentes, así como la composición social de los afiliados y sus demandas. Del estudio se desprende que las funciones que cumplió el Centro Gallego en la cuarta y quinta décadas del siglo pasado llaman la atención sobre la necesidad de reconsiderar el papel del movimiento mutualista en el ámbito del sistema de salud, así como el rol que tuvo la etnicidad en y desde esta dimensión particular. Entre el período de crisis y la posterior emergencia de una modalidad sanitaria propia del Estado de Bienestar ${ }^{8}$, la atención de la salud se hallaba fragmentada no solo por la existencia de distintos prestadores sino también por una demanda todavía signada por el origen étnico aun cuando el proceso de nacionalización —entendido como homogeneización- parecía consolidado.

\section{LA ORganización MUtualista y El Centro Gallego}

A comienzos del siglo XX algo más de medio millón de personas se hallaban afiliadas a alguna de las 1200 sociedades de socorro mutuo que existían en la Argentina, la mayoría concentradas en la ciudad capital y la provincia de Buenos Aires, dado el peso que en estos distritos había tenido la inmigra-

${ }^{7}$ La Asociación Española de Socorros Mutuos de Comodoro Rivadavia, una de las más australes del país, cuyo sanatorio se inauguró en 1959 es un ejemplo de las diversas temporalidades a la que nos referimos. Crespo, 2016. Una tipología de estas sociedades étnicas en González Bernaldo de Quirós, 2013: 161-166.

8 Más allá de los debates que origina el uso del término en el caso argentino o de las conceptualizaciones propuestas más recientemente -Estado de compromiso o Estado social, entre otros-, utilizamos el término clásico de Estado de Bienestar siguiendo las consideraciones realizadas por Andrenacci, Falappa y Lvovich, 2004. 
ción europea que las animaba. En efecto, entre las instituciones se destacaban las que habían organizado las colectividades de inmigrantes -españolas e italianas en particular-. Con una trayectoria que se remontaba a mediados del siglo XIX, habían recibido el impacto de los flujos masivos de población de manera que para 1914 estas sociedades nucleaban al $60 \%$ de los socios que registró el censo nacional. Es cierto que tenían una gran diversidad, desde las ubicadas en pequeñas localidades con poco más de un centenar de socios, hasta las que computaban miles de afiliados en las grandes ciudades. En tal sentido, destacaba la poderosa Asociación Española de Socorros $\mathrm{Mu}$ tuos, como la calificara el Dr. Domingo Bórea funcionario del Ministerio de Agricultura de la Nación y prestigioso cooperativista, que congregaba a más de 22000 afiliados, cifra cercana únicamente a las sociedades de los trabajadores de las empresas del Ferrocarril Sud y del Ferrocarril Central Argentino, entre las más importantes por oficio ${ }^{9}$. Sin embargo, a diferencia de la española, en estas los aportes eran descontados por las respectivas empresas.

Ahora bien, considerando que estas instituciones eran «sociedades de seguro contra las enfermedades $\rangle^{10}$, no cabe duda de su relevancia en el ámbito de la salud ${ }^{11}$. Un hecho que no sorprende si tenemos en cuenta que a comienzos del siglo XX el sistema público sanitario estaba en manos de instituciones de beneficencia (muchas de ellas subvencionadas por el Estado), o bien de los municipios que, salvo en la ciudad de Buenos Aires, contaban con escasos recursos. $\mathrm{Y}$ es que, salvo algunas intervenciones, tanto los gobiernos provinciales como el Estado nacional desempeñaban un papel muy restringido en el área ${ }^{12}$.

El Centro Gallego, una de estas instituciones, había sido fundado en 1907 con fines sociales y asistenciales. Un lustro después un cambio en el estatuto habilitó la prestación de servicios médicos, por lo que rápidamente alcanzó los 6646 socios que registró el censo nacional de población ${ }^{13}$. Aunque sus afiliados eran bastante menos que los de entidad española mencionada, esa cifra se acercaba a la del conjunto de las otras diez instituciones de origen peninsular existentes en la ciudad - la mayoría con varias décadas de funcio-

9 Tercer Censo Nacional (TCN), T. X: 240.

10 Ibidem T. X: 91.

11 Con respecto a la emigración española a América, aunque esta modalidad asociativa de atención de la salud no se estableció en todos los países receptores — en México prevaleció la beneficencia en manos de la élite peninsular-, esta también era la situación del caso cubano. Sin embargo, allí las principales prestaciones sanitarias estaban animadas por entidades regionales como el Centro Gallego de La Habana, con importante penetración en el territorio de la isla. Gutiérrez Forte, 2012.

12 Belmartino, 2005: 23-32.

13 TCN T. X: 244. Fernández Santiago, 2008: 208. 
namiento ${ }^{14}$ —. Un hecho esperable si consideramos que, según estimaciones de José Moya, cerca de la mitad de los españoles residentes en la capital argentina había nacido en Galicia ${ }^{15}$. Lo cierto es que aun en el conjunto de las sociedades mutuales y étnicas existentes en el país el Centro Gallego solo era superado por la Asociación Española de Socorros Mutuos de Buenos Aires ${ }^{16}$.

Para 1926, cuando el Censo de Mutualidades revelaba que el total de asociados se mantenía estable ${ }^{17}$, los afiliados al centro se habían triplicado —unos 17000 - , siguiendo una tendencia que iba a continuar pese a la marcada disminución de la oleada migratoria de las décadas siguientes. En efecto, como vemos en la figura 1, los años treinta y parte de los siguientes fueron de gran expansión, al punto que hacia 1935 el Centro Gallego casi duplicó el número de miembros de la asociación española ${ }^{18}$. Aunque para este período no contamos con estadísticas censales, semejante crecimiento también era notable en el conjunto del movimiento mutualista. En efecto, si las 1500 entidades de 1940 representaban una cuarta parte más que las de 1926 y sus miembros se habían duplicado, la entidad gallega había llegado a congregar al 7,3\% de los afiliados de todo el país ${ }^{19}$, siendo que, en 1914, época de esplendor, la asociación española de Buenos Aires concentraba el 4,4\% de los individuos que integraban el sistema.

14 Así, la Sociedad Catalana, creada en 1857, contaba con 1568 socios, cifra análoga a La Unión Española y la Española de Socorros Mutuos de ambos sexos. Junto con las siete restantes - españolas de La Boca, Flores y parroquia de San Bernardo, Centro Balear, Asociación Canaria y Unión Gallega Primitiva-, congregaban 7009 afiliados. TCN T. X: 240-245.

15 Con un millón y medio de habitantes, en 1914 la ciudad de Buenos Aires contaba con 304529 españoles —el $60 \%$ de los residentes en el país-. Los censos nacionales no distinguen el origen regional de los extranjeros, de manera que las estimaciones deben realizarse de manera indirecta a través de los libros del Registro Civil de las Personas, las listas de socios de las organizaciones mutuales, etc. Con todo, se sabe que el asentamiento de los gallegos fue muy dispar. Desde una proporción superior al $70 \%$ de los peninsulares en Avellaneda, municipio de la provincia de Buenos Aires en el límite sur de la Capital Federal, al $13 \%$ en la ciudad de Mar del Plata, por entonces exclusivo centro de veraneo. TCN T. II: 148 y 397. Moya, 2004: 27-28. Farías Iglesias, 2010. Da Orden, 2005.

16 Ninguna de las numerosas sociedades de socorros mutuos del colectivo italiano -el más importante junto con el anterior-, superaba la cantidad de afiliados de este centro. TCN T. X: 250 y 272 .

17 El censo realizado en 1926 registró 1200 entidades que, como en 1914, en reunían medio millón de socios. Las sociedades de origen étnico continuaban prevaleciendo tanto por el número de afiliados (las tres cuartas partes del total) como por el capital que disponían (cerca del $85 \%$ ). Del mismo modo sus gastos hospitalarios duplicaban los del resto de las entidades. Lequerica Ibarrola, 1928.

18 Moya, 2004: 305.

19 En 1940 las 1500 sociedades de socorro mutuo existentes reunían un millón de socios según la Revista de la Federación Médica de la República Argentina (Belmartino et al., 1987: 66). 
Figura 1. Número de socios del Centro Gallego, 1914-1950

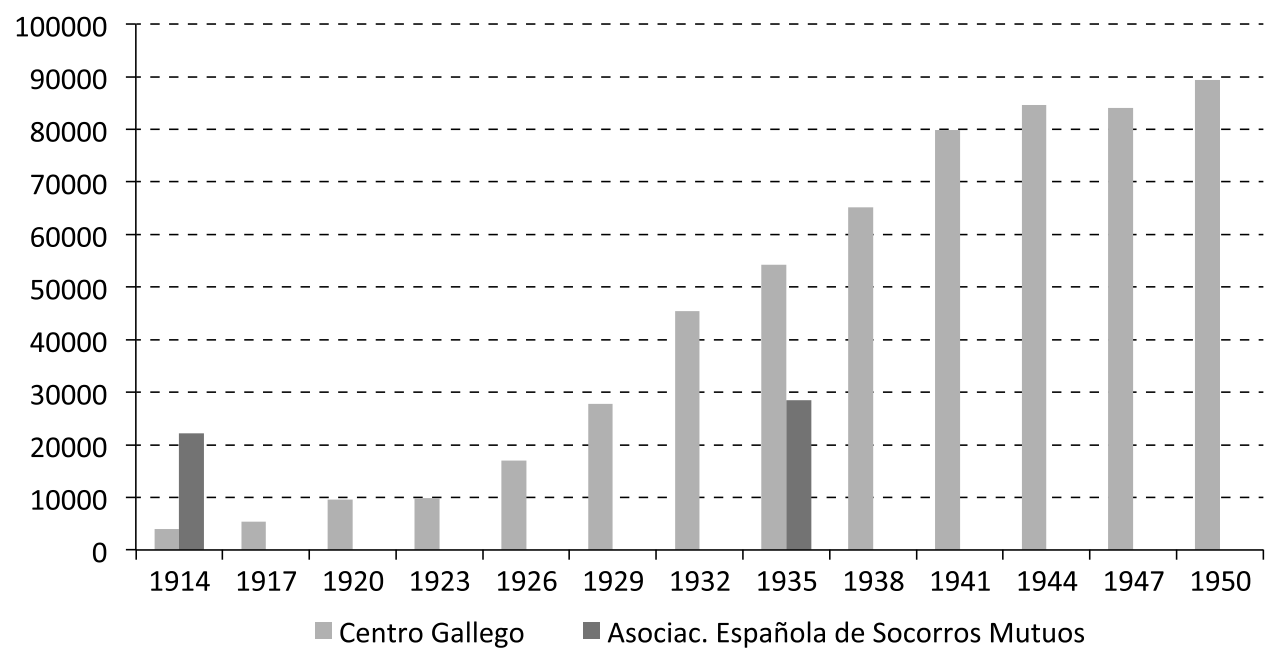

Años seleccionados. Fuente: Galicia. Revista del Centro Gallego (GRCG) XXXIV/450 (Buenos Aires, septiembre de 1950): 22. Fernández, 2001: 144-145. Nota: consideramos el número de socios cada tres años, sin que ello modifique la tendencia.

Lo cierto que el Centro Gallego tuvo un importante desarrollo en los años en que los contemporáneos y también los investigadores de la historia de la salud, señalan la crisis que aquejaba a este movimiento y al conjunto del sistema sanitario. De hecho, aun la declinación que pareció iniciarse a mediados de los años cuarenta fue superada en 1950 cuando el número de socios rondó los 90000 y continúo aumentando ${ }^{20}$. La institución daba cuenta, entonces, de una demanda que, con algunas oscilaciones, no había cesado de crecer pese a la transformación que se estaba operando en la salud pública con el acceso del peronismo al poder. Por lo demás, que se tratara de una institución étnica también contradice, o al menos complejiza, la tendencia integradora de la sociedad argentina tal como sostuvieron los partidarios de la asimilación y aun los defensores del pluralismo cultural para este período.

\section{LAS PRESTACIONES SANITARIAS}

¿Cuáles eran las razones de este crecimiento cuando el Estado comenzaba a tener una política intervencionista que en materia sanitaria se acentuó deci-

${ }^{20}$ En 1960 fueron superados los 100000 afiliados. Cagiao Vila y Peña Saavedra, 2008: 28. 
didamente durante el peronismo? Como señalamos, a poco de fundado el Centro Gallego priorizó la función previsional sobre los objetivos sociales y culturales que interesaban a los dirigentes vinculados con el nacionalismo gallego $^{21}$. Una decisión adoptada en el marco de un sistema de salud que los distintos niveles del Estado, desde la esfera nacional a la provincial, atendían de manera apenas subsidiaria.

Desde esa modificación la entidad empezó a cubrir la atención médica de los socios a domicilio. Sin embargo, respondiendo a una necesidad que la mayoría de estas entidades hacía patente, muy tempranamente el número de prestaciones en consultorios propios fue mayoritario ${ }^{22}$. En 1923 el edificio adquirido tres años antes fue dotado con salas de clínica, cirugía y habitaciones para internación. Poco después fueron comprados varios predios en la zona aledaña hasta que finalmente, en 1931, se difundieron las bases de un concurso para la construcción de un sanatorio-hospital ${ }^{23}$. Según estas, el edificio constaría de cinco plantas y dos subsuelos, con capacidad para más de 300 camas en habitaciones con baño que incluían de dos a cuatro unidades (frente a las salas comunes de la mayoría de los hospitales), varias salas de cirugía, consultorios y otras dependencias. En cinco años se inauguró la primera etapa del edificio, en 1941 la segunda, en tanto que la tercera y última, prevista con un intervalo análogo, se dilató bastante más ${ }^{24}$. Como tantas obras privadas y públicas en los primeros años del peronismo, la inflación y la escasez de materiales de construcción (en su mayoría de importación controlada por el gobierno), afectaron su desarrollo ${ }^{25}$. Así, para afrontar el encarecimiento del proyecto en 1950 debió

21 Fernández Santiago, 2008: 215-216.

22 Según la estadística anual publicada por la revista del centro en 1950, desde 1914 la atención a domicilio oscilaba entre el 10 y el $20 \%$ del total de prestaciones médicas (sin considerar las técnicas). GRCG, XXXIV/450 (Buenos Aires, septiembre de 1950): 22.

${ }^{23}$ Los terrenos ocupaban casi la mitad de la manzana ubicada en la intersección de la avenida Belgrano y la calle Pasco, a unas diez calles del Hospital Español, en el barrio de Balvanera. GRCG, XIII/153, (Buenos Aires, agosto 31 de 1925): 15. También «El Centro Gallego y su obra de Colmena», GRCG, XIV/ 279 (Buenos Aires, abril de 1936): 3-5. Las bases del concurso en GRCG, XIX/225 (Buenos Aires, septiembre de 1931).

${ }^{24}$ El edificio fue proyectado por el estudio de los arquitectos Acevedo, Becú y Moreno, uno de los 43 que participaron en el concurso público realizado por el Centro Gallego con la colaboración de los colegios de arquitectos y de ingenieros de la Capital Federal. Esta y otras referencias sobre la obra fueron ampliamente publicitadas por la prensa porteña. Ver, por ejemplo, La Razón, 25 de julio de 1932. El Hogar, Buenos Aires, 1 de mayo de 1936. La Nación, Buenos Aires, 24 de marzo de 1933 y 6 de septiembre de 1939. Centro Gallego, Haynes publishing company archive (HPCA), British Library, https://eap.bl.uk/archive-file/EAP375-1-1-215.

25 Sobre este tema y la crisis que afectó al país entre 1949 y 1952, puede verse, entre otros, Gerchunof y Antúnez 2002. 
lanzarse un empréstito interno por tres millones de pesos. De manera que la inauguración del último tramo recién pudo efectuarse en $1953^{26}$.

Ahora bien, las prestaciones hospitalarias eran casi inexistentes entre las sociedades de carácter étnico y aun entre las de oficio: los ferroviarios, uno de los sectores más importantes del país, recién en 1940 contaron con un hospital gracias a la adhesión de los socios de dos de las entidades mutuales del $\mathrm{ramo}^{27}$. De hecho, los gastos que ocasionaba la internación eran una de las cuestiones que derivaron en la crisis del sector ${ }^{28}$. Así, el Hospital Español de Buenos Aires dependiente de la Sociedad Española de Beneficencia, por mucho tiempo fue el único de ese origen, de manera que las instituciones de ese colectivo debieron establecer una red de reciprocidades si querían internar a sus socios en esa institución. Del mismo modo, el Hospital Italiano, el Británico, el Francés y el Alemán, también fundados en la segunda mitad del siglo XIX, se hallaban sostenidos por sociedades de beneficencia ${ }^{29}$.

A pesar del intervencionismo estatal de los años treinta, según datos oficiales, aún en 1940 la atención pública hospitalaria continuaba dependiendo de las administraciones municipales (en mucho menor grado del gobierno nacional), y se hallaba concentrada en la ciudad de Buenos Aires. En efecto, aunque en la capital funcionaban 37 de los 450 hospitales del país, allí se concentraba el $27 \%$ de las internaciones - más de la cuarta parte procedente de las provincias - y cerca de la mitad de los médicos ${ }^{30}$. Siete de estos hospitales eran de «colectividades extranjeras» como los denomina la publicación oficial y cubrían el $16 \%$ de las internaciones realizadas en la ciudad.

Si nos detenemos en la franja de población que atendían los diecisiete hospitales de «colectividades» del país ${ }^{31}$, los servicios estaban todavía más concen-

26 GRCG, XXXIII/ 442 (Buenos Aires, diciembre 1949). Fernández Santiago, 2008: 211.

27 En 1940 los sindicatos La Fraternidad y la Unión Ferroviaria, adquirieron un edificio para el Hospital Ferroviario con 50000 adhesiones voluntarias de los afiliados de las respectivas organizaciones de socorro mutuo. Un año antes, también el Círculo de Obreros Católicos de la ciudad de Rosario había inaugurado un importante sanatorio. Belmartino et al., 1991: 105. Mauro, 2015: 195.

28 Así lo señala Susana Belmartino 2005: 72-78, quien para este período analizó el funcionamiento de la Asociación Obrera de Socorros Mutuos.

29 Belmartino, 2005: 28; Jankilevich, 2017. El Hospital Israelita y el más pequeño Hospital Sirio Libanés, también de entidades benéficas, iniciaron sus actividades en 1921 y 1937, respectivamente.

30 Aunque estos hospitales representaban el $8 \%$ del total, ejecutaban el $42 \%$ del conjunto de gastos. Anuario Geográfico Argentino. Publicación oficial (AGA), 1941: 567-69, 574-75.

31 Además de los siete hospitales sostenidos por colectivos migratorios en la ciudad capital otros diez se hallaban en las provincias con mayor recepción migratoria (tres en la de Buenos Aires, cuatro en Santa Fe, dos en Córdoba y uno Entre Ríos). AGA, 1941: 567. 
trados. En efecto, el $60 \%$ de sus pacientes se internaron en los establecimientos de la ciudad de Buenos Aires, pese a que en la época de mayor inmigración allí los extranjeros representaban poco más de un tercio de los residentes en el país ${ }^{32}$.

¿Era este un indicio de que las afinidades de carácter étnico se hacían extensivas a la atención médica? Además de la fragmentación del sistema de salud que suponía la existencia de diversas instituciones públicas y privadas, ¿puede verse aquí otra forma de segmentación? Así parecieran ratificarlo las estadísticas de la ciudad. En 1939, por ejemplo, el $64 \%$ de las internaciones de los hospitales de «extranjeros» (como se mencionan en la fuente) tenía ese origen. La proporción llegaba al 79 \% en el caso del Hospital Español y solo era superada por el Hospital Israelita. Esta relación prácticamente se invertía en las instituciones sostenidas por el municipio, donde el $67 \%$ de los internados eran argentinos, una proporción análoga a la del total de la población ${ }^{33}$. El hecho que más de la mitad de los pacientes de aquellos provinieran del interior del país - dos tercios más que en el resto de las instituciones-, tiende a reforzar la idea de que las «preferencias» de carácter étnico no jugaban un papel menor a la hora de buscar atención hospitalaria. Más adelante el análisis de la sociedad que estudiamos permitirá avanzar en esta línea.

¿Qué lugar ocupaba el Centro Gallego en este panorama? Aunque los nosocomios hasta aquí considerados no son asimilables al sanatorio mutual - sea por el tipo de usuario y el origen de los recursos, sea por su forma de gestión-, servirán como referencia para ponderar los servicios del centro ${ }^{34}$.

Así, tomando los indicadores ofrecidos por las estadísticas municipales para las prestaciones hospitalarias, el cuadro 1 muestra el crecimiento que tuvo el sanatorio del Centro Gallego tanto en internaciones, como en cirugías y partos, de acuerdo con el incremento de socios y la ampliación de las ins-

32 Según el censo municipal de 1936 el $36 \%$ de los habitantes de la ciudad de Buenos Aires eran extranjeros. República Argentina, Municipalidad de la Ciudad de Buenos Aires, Cuarto Censo General, 1936 Población, Buenos Aires, 1939, T. II

33 En febrero de 1939, mes al que corresponden los datos indicados, fueron internados 1623 pacientes en los hospitales italiano, español, alemán, británico, francés, israelita y sirio libanés. En los nosocomios de la ciudad se internaron otros 9517 individuos - 3366 de origen extranjero- Como veremos, esta tendencia apenas varió en el decenio siguiente. Municipalidad de la Ciudad de Buenos Aires Revista de estadística municipal de la ciudad de Buenos Aires, (REM), LII No 616, 617, 618, (enero, febrero, marzo 1939): 41.

34 Solo en los años sesenta del siglo pasado la estadística municipal incluyó datos sobre el sanatorio del centro junto con los de otras instituciones privadas «con fines sociales», de manera que para el período analizado consideraremos la información hospitalaria que figura en la REM y para la institución gallega la que aparece en Galicia, su revista oficial. La selección de los meses y años estuvo condicionada por los números disponibles de la publicación oficial. Un análisis sobre dichas estadísticas en Zuloaga y González Bollo, 2015. 


\section{Cuadro 1. Prestaciones mensuales del Centro Gallego \\ Y DE LOS "HOSPITALES EXTRANJEROS” DE LA CIUDAD DE Buenos Aires en aÑos SElECCIONADOS}

\begin{tabular}{|c|c|c|c|c|c|c|c|}
\hline & \multicolumn{2}{|c|}{1930} & \multicolumn{2}{|c|}{1939} & \multicolumn{2}{|c|}{1950} \\
\hline & & $\mathbf{N}^{\circ}$ & $\% 1 \mathrm{~s} / 2$ & $\mathbf{N}^{\circ}$ & $\% 1 \mathrm{~s} / 2$ & $\mathbf{N}^{\circ}$ & $\% 1 \mathrm{~s} / 2$ \\
\hline \multirow{2}{*}{ Internaciones } & 1. C. Gallego & 89 & \multirow{2}{*}{5} & 139 & \multirow{2}{*}{8} & 248 & \multirow{2}{*}{10} \\
\hline & 2. H. Extranj. & 1434 & & 1653 & & 2368 & \\
\hline \multirow{2}{*}{ Cirugías } & 1. C. Gallego & 149 & \multirow{2}{*}{$\mathrm{s} / \mathrm{d}$} & 259 & \multirow{2}{*}{$\mathrm{s} / \mathrm{d}$} & 705 & \multirow{2}{*}{47} \\
\hline & 2. H. Extranj. & $\mathrm{s} / \mathrm{d}$ & & $\mathrm{s} / \mathrm{d}$ & & 1506 & \\
\hline \multirow{2}{*}{ Partos } & 1. C. Gallego & 22 & \multirow{2}{*}{116} & 44 & \multirow{2}{*}{51} & 95 & \multirow{2}{*}{$\mathrm{s} / \mathrm{d}$} \\
\hline & 2. H. Extranj. & 20 & & 86 & & $\mathrm{~s} / \mathrm{d}$ & \\
\hline
\end{tabular}

Fuentes: GRCG, XVIII/207 (Buenos Aires, marzo 1930), XXVI/314 (Buenos Aires, marzo 1939) y XXXIV/450 (Buenos Aires, septiembre 1950). REM, XLII/3 (Buenos Aires, marzo 1930): 29 y 30, LII/616, 617, 618, (enero, febrero, marzo 1939): 41 y 42. Anuario Argentina Ilustrada. Year Book, (AAI) River Plate Publishing C., Buenos Aires, Talleres Buenos Aires Herald, 1953: 201. Nota: Las cifras corresponden al mes de febrero de cada año, salvo para 1950 en que se tomó el promedio mensual.

talaciones. Esto también es observable en los servicios hospitalarios de los colectivos migratorios, más allá de las oscilaciones existentes ${ }^{35}$. El Hospital Español, por ejemplo, en 1950 contaba con 576 camas, frente a las 250 de $1910^{36}$. Lo interesante aquí, es que la tendencia expansiva del establecimiento gallego se observa también en relación con los siete nosocomios considerados. En efecto, la proporción de sus prestaciones de internación también fue en aumento y la atención de partos, aunque descendió en términos relativos, continuó destacándose habida cuenta que solo tres de los hospitales (Francés, Alemán e Israelita) brindaban este servicio. Pero donde este sanatorio parece distinguirse es en los servicios quirúrgicos. En efecto, aunque no contamos con datos para los años previos, en 1950 allí se practicó casi la mitad de las cirugías realizadas en todos los hospitales de antigua tradición ${ }^{37}$.

35 Por distintos factores las cifras de los indicadores analizados varían tanto mensual como anualmente, la distorsión que esto supone no debería afectar la comparación entre instituciones realizada en el mismo mes/año. De todos modos, aquí solo queremos señalar una tendencia.

36 AAI, 1953: 201. GRCG, XXXIV/450 (Buenos Aires, septiembre 1950).

37 Para 1930 y 1939 la estadística municipal solo ofrece datos agregados para los hospitales bajo la gestión del gobierno nacional y de colectivos migratorios. La proporción del Centro Gallego en ese caso pasó del $2 \%$ al $6 \%$ respectivamente. Las fuentes son las citadas en el cuadro 1. 
Por lo demás, la atención médica en consultorios externos de esas instituciones (que la estadística consigna en 1950), solo era una quinta parte superior a la que brindaba el Centro Gallego (509 000 anuales frente a las $412000 \mathrm{del}$ último). El dato también resulta interesante si tenemos en cuenta los hospitales nacionales y municipales, objetivo prioritario de la política sanitaria de entonces. En ese caso, los servicios en los consultorios del sanatorio gallego alcanzaron el $29 \%$ y el $17 \%$ de los que ofrecieron en ese año los establecimientos del Estado nacional y municipal respectivamente ${ }^{38}$.

Cuadro 2. Prestaciones mensuales del Centro Gallego y de hospitales No MUNiCIPALES DE LA CIUDAD DE Buenos Aires EN AÑos SElECCIONADOS

\begin{tabular}{|c|c|c|c|c|c|}
\hline & \multicolumn{2}{|c|}{1930} & \multicolumn{2}{|c|}{1939} \\
\hline & & $\mathbf{N}^{\circ}$ & $\% 1 \mathrm{~s} / 2$ & $\mathbf{N}^{\circ}$ & $\% 1 \mathrm{~s} / 2$ \\
\hline \multirow{2}{*}{ Odontología } & 1. C. Gallego & 1161 & \multirow{2}{*}{45} & 3573 & \multirow{2}{*}{125} \\
\hline & 2. H. no municipales & 2598 & & 2842 & \\
\hline \multirow{2}{*}{$\begin{array}{l}\text { Farmacia } \\
\text { (recetas) }\end{array}$} & 1. C. Gallego & 13275 & \multirow{2}{*}{19} & 27101 & \multirow{2}{*}{26} \\
\hline & 2. H. no municipales & 71260 & & 105365 & \\
\hline
\end{tabular}

Fuentes: GRCG, XVIII/207 (Buenos Aires, marzo 1930), XXVI/314 (Buenos Aires, marzo 1939) y XXXIV/450 (Buenos Aires, septiembre 1950). REM, XLII/3 (Buenos Aires, marzo 1930): 29 y 30, LII/616, 617, 618, (enero, febrero, marzo 1939): 41 y 42. AAI, 1953: 201. Nota: Los hospitales no municipales figuran bajo la denominación «Otros hospitales» en las estadísticas, un total de 14 nosocomios donde se incluyen los establecimientos nacionales (Hospital Rivadavia, de Niños, Militar, etc.) junto con los «extranjeros». Las cifras corresponden al mes de febrero de los años considerados.

Existía otro tipo de prestaciones que en los años treinta el Departamento de Estadística sólo computaba para el conjunto de hospitales no gestionados por el municipio que nos permiten ampliar el análisis. Se trata de los servicios odontológicos y farmacéuticos que, como vemos en el cuadro 2, se habían incrementado en términos absolutos tanto en el sanatorio del centro como en dichas instituciones. Si ambos items daban cuenta de un aumento en la calidad de la atención sanitaria, en términos relativos - y aun absolutos en el área de odontología-, esto era más acentuado en el caso que estudiamos, señalando una tendencia que ya no se detuvo ${ }^{39}$.

38 AAI, 1953: 201. GRCG, XXXIV/450 (Buenos Aires, septiembre 1950).

39 En el mismo mes que se indica en el cuadro, los servicios de odontología del Centro Gallego alcanzaron la cifra de 5099, en tanto que la farmacia elaboró 35340 recetas, esto 
Es cierto que, como muestra la figura 1, tal crecimiento se vincula con el aumento de afiliados de los años treinta, aunque es muy probable que el tipo de prestaciones sanitarias alimentaran a su vez semejante expansión. De hecho, a juzgar por las estadísticas consideradas, frente a los hospitales de colectivos migratorios, el Centro Gallego se diferenciaba tanto en prestaciones quirúrgicas como en atención de partos y en consultorio. Esto sin contar las visitas profesionales a domicilio, propias de un servicio mutual, que solo efectuaban los hospitales municipales ${ }^{40}$.

Existía una correlación entre estos indicadores y el número de profesionales universitarios incorporados, una información que lamentablemente las estadísticas municipales no brindan. Si en 1938 este sanatorio contaba con 71 médicos, mientras que 28 concurrían a los domicilios de los socios, tanto en la ciudad capital como en el Gran Buenos Aires, en 1950 ese número había pasado a 108 y 48 respectivamente ${ }^{41}$. Se trataba de una oferta profesional altamente especializada si consideramos que en 1932 solo el $20 \%$ de las prestaciones brindadas en los consultorios recayeron en médicos clínicos $^{42}$. Como se ha señalado, el avance de las distintas ramas de la disciplina y la creciente medicalización social marcaban esa tendencia desde las primeras décadas del siglo $\mathrm{XX}^{43}$. Así, aunque en 1950 la clínica médica había aumentado un $6 \%$, el crecimiento de los servicios técnicos (radiografías, electrocardiogramas, análisis de laboratorio, etc.) daba cuenta de la también creciente complejidad de las prestaciones sanitarias ${ }^{44}$.

La trayectoria de estos profesionales - también insertos en instituciones como el Hospital de Clínicas, dependiente de la Facultad de Medicina de la

supuso un crecimiento del $42 \%$ y el $31 \%$ con relación a 1939 respectivamente, mayor en proporción al número de socios (28 \% entre ese año y 1950). GRCG, XXXIV/450 (Buenos Aires, septiembre 1950). REM, XLII/3 (Buenos Aires, marzo 1930): 29; LII/616, 617, 618, (enero, febrero, marzo 1939): 41.

40 En dichos hospitales las visitas a domicilio representaron el $1 \%$ y el $7 \%$ de los servicios en consultorios externos (1930 y 1939 respectivamente). Aunque estas cifras pueden ser muy variables, los médicos de radio del Centro Gallego cubrían entre el $10 \%$ y el $15 \%$ de esas prestaciones. GRCG, XXXIV/450 (Buenos Aires, setiembre 1950).

41 GRCG, XXV/302 (Buenos Aires, marzo 1938) y XXXIV/445 (Buenos Aires, marzo-abril 1950).

42 La proporción es muy significativa si tenemos en cuenta que en 1937 la Asociación Obrera de Socorros Mutuos, única de la que tenemos información, la clínica médica representaba dos tercios del total. GRCG, XIX/260, (Buenos Aires, julio 1934): 11 y XXXIV/450 (Buenos Aires, septiembre 1950): 16. Belmartino, 2005: 75.

43 Ibidem.

44 Así, si en el lapso comprendido entre 1934 y 1950 el total de prestaciones había aumentado un $150 \%$, los distintos servicios técnicos lo hicieron en un $290 \%$. GRCG, XIX/260, (Buenos Aires, julio 1934) y XXXIV/450 (Buenos Aires, septiembre 1950). 
Universidad de Buenos Aires, donde varios ejercían la docencia-, así como la continuidad de su actuación en el sanatorio del Centro debió incidir en el tipo de servicios ${ }^{45}$. Un sentido de pertenencia se puso de manifiesto con la formación de la Asociación Médica del Centro Gallego, que además de la defensa de los intereses corporativos debió buscar cierta visibilidad externa ${ }^{46}$.

Lo cierto es que la expansión de la sociedad mutual y su sanatorio se tradujo en el crecimiento del personal que en 1950 superó los 500 individuos entre profesionales (médicos, enfermeros y técnicos), empleados administrativos, de limpieza, cocina o mantenimiento, más del doble de los ocupados a mediados de los años treinta ${ }^{47}$.

Ahora bien, ¿con qué recursos se solventaban estos servicios? Como se espera de una entidad de socorro mutuo, el grueso de los ingresos provenía de las cuotas sociales, de ahí la importancia de las afiliaciones (sobre todo de jóvenes) y la retención de los socios. Los ingresos que suponían la atención en el sanatorio, las donaciones $\mathrm{y}$, como veremos, algunas inversiones ocupaban un lugar secundario. Por la prioridad dada a estos servicios, casi la totalidad de los recursos eran destinados a gastos en salud, mientras que la beneficencia, repatriación, panteón social, asesoría jurídica o cultura apenas sumaban el $5 \%$. El aumento de los gastos se hallaba, pues, en relación directa con la atención de la salud y las inversiones que suponía. Así, en 1938 las erogaciones superaban $\$ 1200000$, un monto $40 \%$ más elevado que el promedio de lo que gastaban los «hospitales extranjeros» en 1940. Por lo demás, esa cifra representaba nada menos que la mitad de los gastos que realizaba el gobierno de la provincia de Buenos Aires, la más rica del país, en sus dieciséis

45 Entre el $30 \%$ y el $40 \%$ de los médicos prestaban servicio también en instituciones públicas reconocidas como lo hospitales Pedro Elizalde (de niños), Ramos Mejía, Fernández, Rawson o Durand. También es notable la permanencia que muchos tuvieron en la institución. Entre otros, Juan José Beretervide (1895-1988), jefe del servicio de diagnóstico en los años treinta, clínico consultor en los cuarenta y director del sanatorio en la década siguiente, al tiempo que se desempeñaba como Profesor Titular en la Universidad de Buenos Aires. Por otra parte, con el exilio republicano se incorporaron al elenco médico Felipe Jiménez de Asúa, Estanislao Lluesma, Germán Quintela, Antonio Baltar y Gumersindo Sánchez Guisande, los dos últimos con trayectorias de prestigio en Santiago de Compostela. Los datos que figuran en primer lugar se obtuvieron mediante el cruce nominal de los avisos que publicaban los profesionales en la revista del centro y la información sobre el personal del sanatorio. GRCG, XIX/ 235 (Buenos Aires, julio 1932); XXV/302 (Buenos Aires, marzo 1938) y XXXIV/445 (Buenos Aires, marzo-abril 1950). "Juan José Beretervide Premio Konex 1983: Medicina Interna" http:// www.fundacionkonex.org/b1064-juan-jose-beretervide; Aránzazu Díaz-R. Labajo, 2016.

46 GRCG, XXXIII/442 (Buenos Aires, diciembre 1949): 33-34.

47 GRCG, XXIV/279 (Buenos Aires, abril 1936) y XXXIV/443 (Buenos Aires, enero 1950). 
hospitales ${ }^{48}$. Esto ponía en evidencia el papel que desempeñaba la organización mutualista, al menos la entidad aquí considerada, pero también los limitados alcances de la salud pública en manos del Estado.

De hecho, en esos años salió a la luz un fuerte debate sobre la «cuestión hospitalaria», término con el que se aludía a las carencias del sector y que dio origen a diversos proyectos de reforma. La tendencia intervencionista del gobierno militar que tomó el poder en 1943 se hallaba así preparada. Desde la Secretaría de Trabajo y Previsión, dirigida por el coronel Perón, se desplegó una actividad que tuvo como protagonistas a los gremios de los trabajadores, aunque no dejó al margen la acción de estas organizaciones con la creación de la Dirección de Mutualidades — que está por estudiar-, de manera que a partir de 1946 cuando llegó a la presidencia, la política sanitaria fue un leitmotiv de su gobierno. Bajo la gestión de Ramón Carrillo, primero Secretario de Salud con rango ministerial y luego ministro hasta 1954, se diseñó un vasto plan para la construcción de nuevos hospitales y centros de atención, mientras que los gobiernos provinciales también aumentaron su presencia ${ }^{49}$.

En este nuevo contexto, ¿cuál era la situación de la entidad gallega? Como era de esperar, en 1949 los gastos habían aumentado hasta alcanzar los seis millones de pesos. Además de las repercusiones de la inflación y de nuevos rubros como las cargas laborales introducidas por el gobierno, en ello había incidido la ampliación de los servicios que hemos analizado. ¿Era este también el escenario de los hospitales públicos? Pese a la escasez de información y los problemas que supone comparar la administración de una sociedad mutual con la gestión del sector público, si bien no contamos con cifras para la ciudad de Buenos Aires, dos hospitales de importancia análoga servirán a tal efecto. Se trata del Instituto de Cirugía de Haedo, inaugurado a principios de los años cuarenta en la zona oeste de la Capital Federal y del más antiguo Policlínico de la Plata, no muy distante de aquella, con una capacidad de 327 y 487 camas respectivamente. Ubicados en el conurbano o sus cercanías, donde residía buena parte de los socios del Centro Gallego, ambos se hallaban bajo la órbita del Ministerio de Salud y Asistencia Social de la provincia de Buenos Aires, creado en 1947 con el fin de jerarquizar la acción de gobierno en el área ${ }^{50}$. El presupuesto de 1950 había asignado para los dos nosocomios

\footnotetext{
48 GRCG, XXV/308, setiembre de 1938. AGA, 1941: 567 y 574.

49 Belmartino, 2005: 84-85, 109-129. Ramaciotti, 2009. Ross, 1993: 118-122. Un dossier sobre distintos casos provinciales en Biernat y Ramacciotti, 2016.

50 Da Orden, 2014.
} 
un monto que no llegaba a los cinco millones y medio de pesos ${ }^{51}$. Es cierto que esto no da cuenta de la efectiva ejecución de los gastos, sin embargo, el contraste con lo destinado por el centro es significativo tanto si consideramos que las erogaciones del ejercicio anterior (1948-1949) superaban esa cifra, como si tenemos en cuenta que para el siguiente habían sido calculados unos siete millones y medio de pesos ${ }^{52}$. Aun sustrayendo los gastos de administración que abarcaban áreas ajenas al hospital público y los que no se referían a la atención sanitaria, la cifra igualaba a la suma prevista para las dos entidades provinciales. Y ello incluía tanto gastos de personal como partidas para bienes de consumo y mantenimiento. En términos absolutos las asignaciones del centro en dichos rubros casi triplicaban las aprobadas para cada uno de estos hospitales públicos ${ }^{53}$. De este modo, más allá las partidas suplementarias que enviara el gobierno, la realización de análisis, el suministro de medicamentos, la atención de los internados o incluso el mantenimiento de las instalaciones, debían constituir un problema que afectaba la calidad de las prestaciones.

Es cierto que las discusiones en torno al presupuesto que reflejan las actas de la junta directiva daban cuenta de que tampoco esta entidad estaba exenta de las dificultades financieras que afectaban a otras de su tipo ${ }^{54}$. Sin embargo, el Centro Gallego podía ofrecer servicios que el sector público todavía no estaba en condiciones de brindar, al menos en los primeros años de la gestión peronista. Por lo demás, la mayor parte de los nuevos hospitales planificados por la provincia se hallaban en construcción y lo mismo ocurría con los proyectados por el Estado nacional ${ }^{55}$. De hecho, a fines de la primera presidencia de Perón, el propio Ministro de Salud Pública de la Nación señalaba: «Los hospitales y todos los servicios sanitarios están insuficientemente financiados, lo que se traduce en

51 El presupuesto provincial de 1950 destinó para el Policlínico de La Plata \$2 687400 y para el Instituto de Cirugía de Haedo \$2 599705 (el personal estaba compuesto por 447 y 569 individuos en cada caso). Para el conjunto de hospitales y salas de primeros auxilios se habían destinado \$27 700 000. Provincia de Buenos Aires, Cámara de Diputados, Diario de Sesiones (CDDS) 1948-1949, T. IV: 2893, 2927-31, 3067.

52 El total presupuestado era algo superior a los once millones de pesos, el $30 \%$ destinado a la edificación de la última etapa del sanatorio. GRCG, XXXIV/450, (Buenos Aires, setiembre 1950): 23-26.

53 La provincia había asignado $\$ 678000$ y $\$ 782000$ para gastos de consumo del Policlínico de La Plata y del Instituto de Cirugía de Haedo respectivamente, cifra que en el Centro Gallego ascendía a \$2 130 000. CDDS 1948-1950, T. IV: 3067. GRCG, XXXIV /450 (Buenos Aires, setiembre 1950): 26.

${ }^{54}$ GRCG, XXXIV/ 447 (Buenos Aires, junio 1950): 29-32.

55 Da Orden, 2014. Ramaciotti, 2009. 
pobreza, falta de medios técnicos, mala organización y por ende, deficiente servicio» ${ }^{56}$.

No sorprende demasiado, entonces, que un dirigente de la talla de José Espejo, Secretario General de la Confederación General de Trabajadores (CGT), única central obrera del país, en 1950 fuera intervenido en el sanatorio del Centro Gallego, donde al equipo permanente se unió el cirujano Óscar Ivanissevich, por entonces Ministro de Educación. La visita que le hicieran otros dirigentes gremiales, el Intendente de la Capital Federal, gobernadores y funcionarios, culminó nada menos que con la de Perón y su esposa Eva Duarte. Además del reconocimiento a la figura de un dirigente clave para las políticas sindicales del gobierno, el hecho debió suponer un respaldo para la entidad y fue convenientemente difundido en la revista mensual dirigida a los $\operatorname{socios}^{57}$.

\section{LA DIRIGENCIA Y LAS ACTIVIDADES DE GESTIÓN}

Tanto el número de socios como las características de las prestaciones sanitarias, ponen en evidencia que el Centro Gallego parecía estar lejos de la crisis que acusaba el movimiento mutualista. ¿Qué papel desempeñaba al respecto la gestión y los directivos en ella involucrados? Es esta una dimensión del liderazgo en la que los estudios migratorios no se han detenido. Como correlato del interés por los aspectos sociales y culturales que permitían sacar a la luz las sociedades de socorros mutuos, el análisis de sus dirigencias priorizó el papel político, ideológico o socio-cultural, antes que el desempeño al frente de las funciones operativas que estas tenían. Ciertamente con ello se ha demostrado el importante rol de estos líderes en la configuración de las identidades étnicas. No obstante, si esto se justifica para las numerosas asociaciones que tenían fines recreativos o culturales, algunas con importantes derivaciones políticas - la Federación de Sociedades Gallegas o las múltiples entidades locales o micro-regionales de ese origen, por ejemplo ${ }^{58}$ - la cuestión no debería soslayarse en las del tipo que nos ocupa. En ese sentido, los estudios sobre el Centro Gallego han atendido principalmente a las relaciones al interior de la colectividad, el posicionamiento frente al nacionalismo gallego, la Guerra Civil española o el

\footnotetext{
56 Ministerio de Salud Pública de la Nación, Plan sintético de Salud Pública para el periodo 1952-1958 por el Dr. Ramón Carrillo (Buenos Aires, 1951): 94 y 97-98.

57 GRCG, XXXIV/445 (Buenos Aires, marzo-abril 1950: 4-8) y XXXIV/450, (Buenos Aires, setiembre 1950): 7.

58 Díaz, 2007. Núñez Seixas, 2000.
} 
franquismo, problemáticas decisivas tanto para la sociedad de origen como para la de acogida, dada la repercusión que tuvieron en la Argentina ${ }^{59}$. Sin embargo, al mismo tiempo, los directivos tenían que resolver cuestiones específicas nada sencillas en el contexto de crisis económicas recurrentes que afectaban al país. Un ejemplo de ello fue la decisión de instalar una farmacia propia. Como señalaban los contemporáneos, los gastos en medicamentos, cada vez más diversificados, se ubicaban entre los principales factores de encarecimiento de la asistencia mutua ${ }^{60}$. De manera que, además de los establecimientos particulares autorizados en el extenso territorio que cubría el centro, la medida fue estratégica si se tiene en cuenta la limitada proporción de las sumas abonadas a los establecimientos particulares. Como vimos en el cuadro 2, esto favoreció la oferta de la entidad, aunque implicara la incorporación de profesionales y personal calificado, así como un importante esfuerzo de gestión ${ }^{61}$.

De este modo, el movimiento diario suponía disposiciones que involucraban la contratación y el trato con un personal cada vez más numeroso y de variada calificación, la adquisición de equipamiento y suministros — drogas, ropería o alimentos-, así como el mantenimiento de las instalaciones. Esto sin mencionar la complejidad que supuso la ejecución de las obras de edificación a lo largo de más de dos décadas. Como señala el órgano oficial refiriéndose a la priorización de las obras del sanatorio frente a las del teatro: «Mientras éstas continuasen, los servicios mutualistas no podían sufrir el más leve tropiezo, ya que es la parte más delicada, y, por lo tanto, más cuidada que tiene que afrontar el Centro» ${ }^{62}$. Aunque estas afirmaciones suponían un posicionamiento en el contexto de enfrentamiento entre «neutralistas» y republicanos, no debe olvidarse que los socios probablemente prefirieran que sus aportes derivaran en mejores servicios sanitarios antes que en las actividades culturales o políticas que interesaban a los sectores galleguistas y a los intelectuales que pugnaban por el liderazgo. Lo cierto es que la consideración de estas cuestiones aporta otro cariz a las luchas al interior de la dirigencia.

Las notas de la revista del centro iban en la misma línea. Aunque se incluían artículos literarios y de interés cultural, mes a mes se priorizaba la información sobre el movimiento financiero, las compras efectuadas, el nú-

59 De Cristóforis, 2014; 2015. Díaz, 2012. Fernández Santiago, 2001.

60 Belmartino, 2005: 73.

61 Los pagos a las farmacias particulares oscilaron entre la cuarta y la quinta parte de las erogaciones en medicamentos a lo largo del período. De ahí que entre 1934 y 1949 el personal de farmacia pasara de dieciséis a treinta y dos y la compra de insumos implicara la realización de licitaciones y el trato con un amplio abanico de empresas. GRCG, XXII/261 (Buenos Aires, agosto 1934) y XXXIV/443 (Buenos Aires, enero 1950).

62 GRCG, XXVII/ 302 (Buenos Aires, marzo 1938): 9. 
mero de prácticas sanitarias, los socios incorporados o la transcripción de las actas de sesiones de la junta directiva. Al ir más allá de la obligación de publicitar la convocatoria a elecciones o el balance anual exigido por el gobierno a través de la Inspección General de Sociedades Jurídicas, la dirigencia parecía querer dar cuenta de la complejidad y eficiencia de su gestión. Además del aumento del personal administrativo bajo la órbita de un gerente y un subgerente, lo mismo puede decirse de la incorporación de contadores y abogados o de la creación de comisiones que incluían al personal médico y especializado ${ }^{63}$.

Todo lleva a pensar en el criterio empresarial con que se conducían, o debían conducirse, los asuntos del centro. Una lógica que suponía la utilización de técnicas actuariales que los dirigentes mutualistas habían preconizado desde los años veinte y no dejaban de señalar todavía en los cuarenta ${ }^{64}$.

Así, como otros análisis han demostrado ${ }^{65}$, los más altos directivos eran exitosos comerciantes, industriales, financistas o profesionales (actividades muchas veces combinadas) ${ }^{66}$. Más allá de la vocación o el poder y prestigio que quisieran alcanzar, las competencias empresariales y las influencias relacionales no eran un capital desdeñable para el desempeño de la gestión ${ }^{67}$. Así lo evidencia la toma de decisiones y también de riesgos que implicaba la construcción del sanatorio-hospital, la adquisición de diversos bienes inmuebles dentro y fuera de la ciudad de Buenos Aires, la inversión en bonos públicos o la emisión de un empréstito interno para finalizar la tercera etapa del

63 GRCG, XXXIII/440 (Buenos Aires, octubre de 1949): 3-4 y XXXIII/442 (Buenos Aires, diciembre de 1949).

64 Esto se observa en la restricción de la admisión de socios en 1933, a la espera de la ampliación de los servicios, o en el detalle del número y composición etaria de los mismos. Sobre la posición de los dirigentes mutualistas al respecto ver Cabrera, Garat y Martínez Garda, Boletín del Museo Social Argentino (BMSA), XXXII/259-60, enero-febrero, 1944: 22-30. GRCG, XIX/260 (Buenos Aires, setiembre 1934): 3.

65 Devoto y Fernández, 1990.

66 Entre ellos Laureano Alonsopérez, tres veces presidente hasta 1935, cuyas actividades en el sector inmobiliario trascendieron a Uruguay; José Villamarín Álvarez, dos veces presidente, importante empresario junto con su sobrino, José Villamarín Prieto que en 1954 sucedió a Javier Vázquez Iglesias, destacado comerciante e industrial en el rubro automotriz. Por las influencias que podían ejercer en distintos ámbitos, también se distinguen Eleodoro Friol, presidente del Centro Unión Corredores de Comercio, y José Neira Vidal, abogado de profesión y Apoderado General de la Municipalidad de la Ciudad de Buenos Aires hasta 1946. Durante el período que consideramos al menos cuatro de los presidentes del centro formaron parte del directorio del Banco de Galicia o del Banco Español del Río de la Plata. Bonardi, 2006. De Cristóforis, 2015. Fernández Santiago, 2008: 213-214.

${ }^{67}$ Como ha señalado Núñez Seixas (2006), la experiencia profesional contribuye a explicar las condiciones que hacen posible el liderazgo. 
sanatorio ${ }^{68}$. Con otra magnitud, estas acciones no eran ajenas a otras mutuales o incluso centros sociales y recreativos, de ahí la importancia de considerar las funciones de gestión y las competencias que suponían.

Más allá del declarado apoliticismo de la entidad, las relaciones con los sectores de poder formaron parte de tales funciones. Intendentes y concejales de la Municipalidad de Buenos Aires, así como las más importantes autoridades políticas y religiosas del país participaron en distintos actos del Centro Gallego, todo ello difundido en los más destacados diarios de circulación nacional ${ }^{69}$. Aunque estas participaciones, a veces solo protocolares, no eran una excepción suponían un reconocimiento simbólico y político - posiblemente también para las autoridades del país, necesitadas de consenso y adhesión-, que solía traducirse en apoyos materiales como la donación de terrenos, el otorgamiento de subsidios ${ }^{70} \mathrm{o}$ la exención de impuestos ${ }^{71}$.

${ }^{68}$ Las inversiones inmobiliarias fueron muy tempranas. Hacia 1950 más de la mitad del capital estaba formado por bienes inmuebles: la sede y el sanatorio central que ocupaban buena parte de la manzana ubicada entre la avenida Belgrano y las calles Pasco, Moreno y Rincón, el sanatorio de Valentín Alsina (Lanús) y otros tres predios ubicados en esa localidad del conurbano y en otros municipios de la provincia de Buenos Aires. A las cuentas bancarias y plazos fijos, se sumaba la inversión en valores mobiliarios (9\% del capital): bonos del Crédito Argentino Interno emitido en 1937, títulos del Banco Central de la República Argentina, de la Municipalidad de Buenos Aires y de la provincia homónima, así como acciones de una empresa constructora. GRCG, XIII/153 (Buenos Aires, agosto 1925): 15 y XXXIV/450, (Buenos Aires, setiembre de 1950): 11-12.

69 Estos contactos se observan en los años veinte con figuras como José Luis Cantilo, Intendente de la ciudad de Buenos Aires, o el presidente Marcelo T. de Alvear. En 1931 el presidente Agustín P. Justo concurrió con parte de su gabinete a la colocación de la piedra fundamental del sanatorio, en 1936 el Arzobispo de Buenos Aires y Cardenal Primado Santiago Copello, bendijo la obra ya ejecutada, mientras que en 1941 el vicepresidente Ramón Castillo asistió a la inauguración de la segunda etapa. Véase por ejemplo, El Mundo, Buenos Aires, 14/7/1932. La Razón, Buenos Aires, 19 y 25 de julio de 1932. La Prensa, Buenos Aires, 26 de julio de 1932. La Nación, Buenos Aires, 24 de marzo de 1933 y 6 de septiembre de 1939. El Hogar, Buenos Aires, 1 de mayo de 1936. HPCA.

70 A mediados de los años veinte la Municipalidad de Buenos Aires cedió los terrenos para el panteón social en el cementerio de La Chacarita. En 1934 un decreto del Intendente de Buenos Aires, Mariano de Vedia, eximió al centro del pago de \$54 000 por derechos de construcción. Cuatro años después, un subsidio también municipal ascendió a $\$ 50000$, valor que representaba cerca de la mitad del ingreso mensual que suponían las cuotas de los 60000 socios del centro. Belmartino, Bloch, y Quiroga, 1987: 76. GRCG, XIV/165 (Buenos Aires, agosto de 1926): 10; XXII/255 (Buenos Aires marzo-abril 1934): 4 y XXII/ 280 (Buenos Aires setiembre 1934): 5 .

71 Pese a que la exención de impuestos fue un reclamo desde comienzos de siglo, todavía en 1942 el segundo congreso mutualista argentino lo incluyó entre sus reivindicaciones. BMSA, XXX, 243-244, septiembre-octubre, 1942: 257-265. 
La llegada del peronismo al poder no implicó cambios en este sentido. Como indicamos, una muestra de ello fue la visita al sanatorio del presidente y su esposa con motivo de la cirugía practicada al Secretario General de la CGT. Esto fue seguido de una entrevista de los dirigentes con el primer mandatario que derivó en el otorgamiento de un subsidio de un millón de pesos ${ }^{72}$ - un tercio del costo de finalización de las obras del sanatorio-. Estas relaciones eran particularmente necesarias por cuanto el control estatal de las importaciones (desde ambulancias hasta materiales para la construcción) tenía una incidencia directa en los insumos y las obras de edificación. Más allá de las formalidades, de ahí también los agradecimientos al Ministerio de Industria y Comercio y a otros funcionarios que constan en las actas de reunión de directivos $^{73}$. El interés, por otra parte, no era unidireccional. Además del control que suponía la creación de la Dirección de Mutualidades, la concesión de exenciones y subsidios tanto por parte del gobierno nacional como por el de la provincia de Buenos Aires, daba cuenta del reconocimiento a las instituciones mutuales como organismos concurrentes con la acción estatal en materia sanitaria ${ }^{74}$.

No obstante, al comenzar la nueva década, la revista oficial se hacía eco del «grave problema financiero» que atravesaba la Sociedad Española de Socorros Mutuos y «todas las grandes sociedades mutualistas» por el alza de precios y el aumento de los sueldos. Como resultado esa y otras instituciones habían elevado sus cuotas a valores que oscilaban entre $\$ 8$ y $\$ 11$, mientras el centro la mantuvo en $\$ 5$ «para no desmentir el carácter sumamente popular de nuestra entidad» ${ }^{75}$. Así se evidenciaban los alcances y las dificultades de la dirigencia en la gestión del Centro Gallego, pero también la demanda de una franja de la población cuyo número superaba al de las entidades españolas más exitosas de la época de inmigración masiva. ¿Quiénes buscaban este tipo de atención cuando, como nunca antes, el Estado nacional y también provincial estaba expandiendo los servicios públicos de salud?

72 GRCG, XXXIV/447 (Buenos Aires, junio 1950): 2.

73 GRCG, XXXIII/ 442 (Buenos Aires, diciembre 1949): 7; XXXIV/448 (Buenos Aires, julio 1950): 26, XXXIV/450 (Buenos Aires, setiembre 1950): 34.

74 En efecto, en 1950 se eximió a las entidades mutualistas del pago de impuestos nacionales - entre otros el que gravaba el alcohol— y de la ciudad de Buenos Aires. Por su parte, el ministerio de salud del gobierno bonaerense estaba habilitado para distribuir materiales sanitarios a los hospitales y sanatorios sostenidos por las entidades mutuales y otras de carácter particular. GRCG, XXXV/450, (Buenos Aires, setiembre 1950): 8. Ley 5318 http://www. gob.gba.gov.ar/intranet/digesto/PDF/05318.pdf

75 GRCG, XXXV/452 (Buenos Aires, noviembre 1950): 39. 


\section{LOS SOCIOS Y LA DEMANDA DE SERVICIOS DE SALUD}

Como han señalado los estudios de las migraciones masivas, el éxito de las sociedades de socorros mutuos de origen étnico se vincula fundamentalmente con cuestiones instrumentales antes que culturales o políticas. En efecto, si es cierto que los españoles o los italianos solían optar por las mutuales de su mismo origen, las limitaciones de la sanidad pública y el creciente interés por el cuidado de la salud fueron decisivas. De hecho, resulta notable la correlación existente entre el ingreso de socios y las sucesivas etapas de ampliación de las instalaciones sanitarias del Centro Gallego.

Ahora bien, pese a su denominación, el centro no solo incluía a migrantes gallegos que, por otra parte, también se insertaban en las mutuales panhispánicas $^{76}$. Además de otros peninsulares, podían ingresar extranjeros de distinta procedencia —en atención al origen de los cónyuges, por ejemplo-, y por supuesto argentinos. Es cierto que el primer estatuto limitaba su participación a un tercio de los socios, pero en los años treinta esto fue suprimido para cumplir con exigencias de la legislación nacional77. De este modo, si en 1926 el $54 \%$ de los ingresos estaba representado por gallegos, en su mayoría de La Coruña y Pontevedra, y el $18 \%$ por otros españoles, para 1950 esta composición se había modificado en favor de los nativos. En efecto, en ese año los nuevos ingresantes nacidos en Galicia (sin mayores variaciones en cuanto a las provincias mayoritarias), habían descendido al $27 \%{ }^{78}$. Por lo demás, el $13 \%$ provenía de otra región de España o (minoritariamente) tenía distinto origen migratorio. Una variación acorde con la disminución del flujo proveniente de la península iniciada hacia 1930 que apenas estaba comenzando a revertirse.

No obstante, si estas proporciones remiten al origen del conjunto de socios, no sería exagerado suponer que, hacia 1950, dos de cada diez gallegos de Buenos Aires estuvieran afiliados al Centro Gallego y bastante más hubiera pasado alguna vez por la institución ${ }^{79}$. Asimismo, que cerca del $40 \%$ de los

76 Tal era el caso de la Asociación Española de Socorros Mutuos de Buenos Aires. Fernández, 2001: 144. Moya, 2004: 28.

77 Fernández Santiago, 2008: 212.

${ }^{78}$ Los datos que figuran en el texto y los que siguen, salvo cuando se indique lo contrario, provienen de una muestra de ingresantes en julio y agosto de 1926 y de 1950 (440 y 840 individuos en cada caso). Centro Gallego, Libro de Socios (CGLS), vols. 1926-1929 y 1950-1951.

79 En efecto, si en 1950 unos 24000 gallegos estaban afiliados a este centro (el $27 \%$ de los socios) esto supondría el $16 \%$ de los 150000 que residirían en la ciudad de Buenos Aires hacia 1914 — la mitad de los españoles según Moya (2004: 27)—. Aunque esta relación es arriesgada (pensemos en la mortalidad, los desplazamientos, etc.), no debe estar muy lejos de 
nuevos afiliados fueran españoles cuando el total de extranjeros residentes en la Capital Federal (incluida la importante franja de italianos) no llegaba al $24 \%$ de la población ${ }^{80}$, pone de manifiesto que también la demanda de prestaciones sanitarias daba cuenta del carácter étnico del centro.

Otro tanto puede decirse de una franja de los argentinos - el $60 \%$ de los nuevos socios-, si consideramos el peso de las relaciones familiares ${ }^{81}$. Una parte de los hijos que habían nacido en el país debía encontrarse entre los nativos menores de 13 años que ingresaron ese año - un tercio de los argentinos, más de la mitad nacidos en el sanatorio-, sobre todo si consideramos la afiliación de gallegos en años anteriores -en 1940 representaban el $39 \% 82$. . No parece errado suponer, pues, que hacia 1950 la primera y la segunda generación de inmigrantes de origen galaico representaran bastante más de la mitad de los socios del centro.

De este modo si la internación de extranjeros en los hospitales de los colectivos migratorios parecía indicar que el lugar de origen no era indiferente en este tipo de demanda ${ }^{83}$, el análisis del Centro Gallego pone en evidencia que desde el punto de vista de los sujetos, el cuidado de la salud y las prestaciones sanitarias que implicaba se hallaban configuradas por la etnicidad. Y esto se manifestaba aún a mediados del siglo pasado, cuando el proceso de integración parecía muy avanzado.

Ahora bien, ¿cuál era el perfil socio-económico de estos individuos? En principio no hay que dejar de lado que la institución daba respuesta a las necesidades de sectores que estaban en condiciones de pagar el ingreso y una cuota mensual — $\$ 5$ en 1950, cuando el precio de un kilogramo de pan y una botella de leche era de $\$ 0,55$ y una entrada al cine costaba $\$ 1{ }^{84}$-, además de afrontar la fracción de gastos correspondiente a las prestaciones. No existía en este caso

la realidad, si tenemos en cuenta que el último ingresante de aquel año tenía el número 186 077. Realizamos la comparación con el censo de 1914 ya que el de 1947 no ofrece datos por nacionalidad. TCN, T. II: 148-149; CGLS, 1950-1951, folio 284.

${ }^{80}$ Cuarto Censo General de la Nación (CCGN), T. I: LXIII.

81 La afiliación familiar se aprecia en la secuencia de apellidos y domicilios que se observa en el registro de los libros de ingreso y también en el cruce nominativo del ingresante con el individuo que lo presenta al centro (un requisito de admisión). Un análisis detallado de este tipo para una sociedad de ayuda mutua española en Da Orden, 2005.

82 Sobre 968 socios incorporados entre julio y agosto de 1940. LS, vol. 1939-1940.

83 A lo indicado para 1939 cabe agregar que en el segundo trimestre de 1946 casi las tres cuartas partes de los internados en el Hospital Español eran extranjeros - el promedio de ese indicador en los nosocomios de colectividades era del $60 \%$ - , frente al $24 \%$ de los hospitales municipales. REM, XLIX, octubre-diciembre 1946, 669: 31.

84 Ibidem: 383. Aunque las cifras corresponden al último mes de 1946, los valores de esos alimentos no debieron alterarse debido al control de precios vigente. 
el aporte patronal que era obligatorio entre algunos asalariados y que con el peronismo se extendió a la importante franja de trabajadores de las empresas que fueron estatizadas y a ciertos gremios regulados por la legislación nacional ${ }^{85}$.

Dicho esto, las ocupaciones declaradas al afiliarse dan una idea de la composición social, pese a las dificultades de interpretación que plantean algunas actividades y a la sub-representación de las mujeres ${ }^{86}$. Se trata de una imagen fotográfica que por el curso de la vida laboral en que se hallaba la mayoría de los ingresantes - en 1950 casi dos tercios tenían entre 16 y 40 años-, seguramente iba a modificarse. No obstante, como vemos en el cuadro 3, en la segunda mitad de los años treinta más de la mitad de los socios eran empleados. Junto con los comerciantes, estas categorías ocupacionales representaban el $70 \%$ del total. En contrapartida los trabajadores no calificados tenían muy escasa participación, tal vez por las limitaciones que suponía el pago de la cuota en un contexto de depresión económica. Así, a fines del período tratado se observa un significativo aumento de esa franja, con el $11 \%$ de jornaleros, obreros y obreras, peones, sirvientas y mucamas. Más estable era el caso de los trabajadores calificados, una quinta parte del total en las dos muestras analizadas. Entre los varones aquí sobresalían los choferes, mecánicos, carpinteros, mozos y sastres, mientras que entre las mujeres predominaban las modistas. La mayoría podía, pues, desempeñar su actividad en forma autónoma. Por otra parte, a fines de los cuarenta, el descenso relativo de empleados y en menor medida de comerciantes, tiene como contrapartida el aumento de los afiliados que se hallaban insertos en los extremos del espectro ocupacional. Por un lado, los trabajadores no calificados y por otro los profesionales, los estudiantes de nivel secundario o universitario y los maestros/as y profesores/as, con un importante sesgo de género - en favor de los varones en los dos primeros casos y de las mujeres en el último-. El hecho que en los últimos años del período las ocupaciones de las mujeres hubieran cuadruplicado su participación en la muestra — del $5 \%$ al $19 \%$ - si remitía a una mayor incorporación en el mercado laboral también lo hacía en sectores vinculados con las actividades asociadas al ámbito doméstico.

85 Belmartino, 2005: 113. Belmartino et al., 1991: 113-135

86 A diferencia de las organizaciones mutuales que nucleaban a los trabajadores por ocupación, desde el comienzo podían incorporarse las mujeres. Pese a que los varones predominaban en los primeros tiempos (en 1926 representaban el $78 \%$ de los nuevos ingresos), en 1950 las mujeres llegaron al $55 \%$. De acuerdo con la importante presencia de nativos, la relación entre los sexos reflejaba la composición del conjunto de la población. Con respecto a su inserción laboral, en la mayoría de los casos el dato ocupacional no fue consignado (en el último año mencionado solo el $40 \%$ de las mujeres mayores de 14 años figura con esa información). Muestra citada en nota 78. 
Con los cambios propios de cada período, esta composición mantenía el predominio del comercio que se observa en los orígenes de la institución ${ }^{87}$. Pese a la disminución que se operara con el tiempo, este sector tenía aquí un peso tres veces mayor que el registrado por el censo nacional de 1947 para esta rama de actividad, cuando el $20 \%$ de los ocupados con remuneración se desempeñaba en comercios, bancos o compañías de seguros. Dicha sobre-representación se mantenía frente al conjunto de extranjeros, que en la ciudad de Buenos Aires suponían el $39 \%$ de los ocupados en el sector ${ }^{88}$.

Cuadro 3. OCupación de los Socios VARONES y MUJeres del CENTRO Gallego maYores de 14 años (PORCENTAJES)

\begin{tabular}{|l|c|c|}
\hline & $\mathbf{1 9 3 6 - 1 9 4 0}$ & $\mathbf{1 9 4 6 - 1 9 5 0}$ \\
\hline Trabajadores no calificados & 6 & 11 \\
\hline Trabajadores calificados / autónomos & 20 & 21 \\
\hline Empleados & 57 & 46 \\
\hline Comerciantes/empresarios & 13 & 2 \\
\hline Profesionales & 1 & 3 \\
\hline Maestras/os, profesores/as & 1 & 1139 \\
\hline Estudiantes & 1252 & 2 \\
\hline Total $N^{\circ}$ & 1 & 2 \\
\hline
\end{tabular}

Fuente: CGLS, vols. 1936-1937; 1937-1939; 1939-1940; 1940-1942; 1944-1948,1949-1950 у 1950-1955. Nota: corresponde a una muestra de los años 1936, 1938 y 1940 para la década del treinta y de 1946, 1948 y 1950 para la siguiente (meses de julio y agosto). CGLS, vol. 1936-1937; 1937-1939; 1944-1948 y 1949-1951. La suma de los porcentajes puede ser superior a 100 por el redondeo de las cifras.

Parece claro, pues, que los afiliados al Centro Gallego pertenecían mayoritariamente a los sectores medios urbanos o a los trabajadores ascenso, propios de una sociedad móvil como la Argentina del período. Una característica que se hallaba además pronunciada, si tenemos en cuenta que la clase media

87 Entre 1907 y 1917 el $56 \%$ los ingresantes al Centro Gallego eran empleados y el $13 \%$ comerciantes, en tanto que los trabajadores calificados apenas superaban a los últimos con el $15 \%$. Fernández, 2001: 146.

88 El censo sigue una clasificación ocupacional por ramas de actividad, sin distinguir entre asalariados y propietarios. CCGN, T. I: 67. 
constituía el $30 \%$ de la población urbana económicamente activa del país mientras que los trabajadores autónomos oscilaban entre el $4 \%$ y el $10 \%$ según estimaciones realizadas para 194789 .

En buena medida debía tratarse de pequeños y medianos comerciantes con una franja de empleados, así como de propietarios de talleres que, si nos atenemos a las edades, podían formar parte de las empresas familiares que solían conformar los españoles y otros inmigrantes como vía para el ascenso ${ }^{90}$. Nutrían así una masa no asalariada o que, como los autónomos, algunos trabajadores no calificados e incluso el importante gremio de los empleados de comercio, carecían de la cobertura que brindaban las nacientes obras sociales de los sindicatos ${ }^{91}$. Se trataba, pues, de un sector disponible para recibir la atención sanitaria de la mutual, que además demandaba mejores servicios de salud sin tener que recurrir a una costosa atención privada.

En este sentido, si hay que tener en cuenta los avances de la disciplina, desde la perspectiva de los sujetos también habría que considerar la influencia de la medicalización social en la que había participado la expansión del propio mutualismo ${ }^{92}$. De este modo, el incremento de la atención a domicilio, la recurrencia a especialidades o el notable aumento de partos en el sanatorio en relación con los atendidos en las casas ${ }^{93}$, permite inferir la utilización de servicios sanitarios que se condice con tales expectativas.

89 Torrado, 1992: 15.

90 El desempeño de Eliodoro Friol en el gremio de corredores de comercio también pudo haber influido en este sentido. El Centro Gallego además tenía vinculaciones con entidades como el Centro Unión de Viajantes, el Centro Unión Dependientes de Rosario, la Asociación Patronal Gastronómica y la Asociación Española de Mozos y Cocineros. GRCG, XXII/255, (Buenos Aires, marzo-abril 1934): 5 y 9; XXVII/ 302 (Buenos Aires, marzo 1938): 34; XXXIV/ 451 (Buenos Aires, septiembre 1950): 31 y XXXIV/452 (Buenos Aires, octubre de 1950): 42 y 44. Sobre el papel de la empresa familiar entre los españoles ver Da Orden, 2005.

91 Recién en 1964 los empleados de comercio, cuyos gremios estaban nucleados en la Confederación General de Empleados de Comercio, tuvieron su propio sistema de salud u obra social (el Instituto Médico Mercantil Argentino). Obra Social de los Empleados de Comercio y Actividades Civiles (O.S.E.C.A.C.) https://www.sanfranciscodigital.com.ar/instituciones/obra-social-de-los-empleados-de-comercio-y-activid/

92 González Bernaldo de Quirós, 2013: 169.

93 Si tomamos la relación de atenciones por socio — un indicador que habría que refinar-, la asistencia a domicilio se duplicó, pasando de 0,3 en 1925 a 0,7 en 1950. Esto contrasta con la disminución de los partos atendidos en las casas. Aunque la ampliación del servicio de obstetricia debió ser decisiva, seguramente también lo fue la demanda de las mujeres - en 1950 solo el $1 \%$ de los partos fueron atendidos en los hogares, frente al $48 \%$ de 1934 Asimismo, el aumento de los servicios de odontología, un aspecto que no solo hay que considerar por la dolencia sino también por el cuidado personal que supone, fue creciente - esta atención pasó del $0,3 \%$ al $0,6 \%$ por socio en 1925 y 1950 respectivamente-, y cada vez 
No obstante, ante la eventual necesidad de internación el déficit de la atención hospitalaria en manos del sector público debía ser uno de los principales motivos para afiliarse al Centro Gallego. De este modo, parecía no importar demasiado que la distancia del sanatorio pudiera demandar dos o más horas de transporte público a los que residían en el Gran Buenos (18\% de los nuevos socios en 1950) o mucho más cuando se trataba de localidades más alejadas. Esta razón habría llevado a José Arias, un comerciante de 32 años, a ingresar al centro junto con su mujer y sus dos hijas pequeñas, aun cuando residían en Mar del Plata (a $400 \mathrm{~km}$ de la Capital Federal ${ }^{94}$ ). Más allá que estos socios representaban solo el $3 \%$ de los que tenían su domicilio fuera de la gran ciudad, ¿qué llevaba a estos y otros individuos, aun de las provincias del interior, a pagar al centro una cuota mensual sino la previsión que suponía una atención diferenciada en caso de internación?

La percepción sobre la calidad del servicio, reforzada tanto a través de la prensa comercial como de la revista del centro, que insistía en el mérito científico del cuerpo médico, también debió influir en este sentido ${ }^{95}$. Otro tanto puede decirse de la disponibilidad de profesionales que ofrecía el sanatorio. Si a comienzos de los años treinta los médicos clínicos cubrían ocho horas en distintos turnos y los especialistas una o dos horas diarias, incluidos los sábados, en 1950 los socios podían recibir atención a lo largo de todo el día por alguno de los más de cien profesionales contratados. En distintas franjas horarias era posible encontrar entre cuatro y siete médicos clínicos, además de especialistas que también habían aumentado el servicio. Sin contar las consultas a domicilio, esta oferta era superior a la de los establecimientos estatales. En efecto, aunque hospitales de primera línea y análogas dimensiones como el mencionado Instituto de Cirugía de Haedo o el Policlínico de La Plata tenían alrededor de 80 médicos, en la práctica sus prestaciones solían tener una franja horaria mucho más reducida ${ }^{96}$. Por lo demás, pese a la pla-

más compleja por la inclusión de servicios radiológicos específicos. GRCG, XIV/163 (Buenos Aires, septiembre de 1926); XXII/280 (Buenos Aires, septiembre 1934); XXXV/450 (Buenos Aires, septiembre 1950).

94 Desde 1942 en que se consigna el dato, se registran afiliados cuyos domicilios se hallaban en distintas ciudades de la provincia de Buenos Aires, así como en distritos del interior (Río Gallegos, Comodoro Rivadavia, Córdoba, Tucumán o Resistencia). El ejemplo de Mar del Plata fue tomado de CGLS v. 1950-1951: 192 y 284.

95 Así, en 1950 Galicia daba cuenta de la celebración de una de las sesiones del XXI Congreso Argentino de Cirugía en la sede social, a la vez que señalaba el «legítimo orgullo» y el «prestigio» que ello suponía. GRCG, XXXV/452, (Buenos Aires, noviembre 1950): 24.

96 Los médicos de hospital de la provincia de Buenos Aires tenían una jornada laboral de tres horas establecida por la ley que reglamentó su carrera en 1948. Dando testimonio de la 
nificación del gobierno peronista, en 1950 solo el $2 \%$ de los hospitales construidos tenía el número de camas de este sanatorio, en tanto que el crecimiento de la atención pública en las provincias era de menor envergadura y se hallaba territorialmente dispersa ${ }^{97}$.

Aunque los motivos de esta demanda seguramente obedecen a una complejidad de factores, lo cierto es que parecen ir de acuerdo con las aspiraciones de ascenso de los sectores medios y populares urbanos que, además, eran de origen español o, más específicamente, gallego. Dado el perfil de los afiliados, difícilmente sus demandas podían estar cubiertas por el sistema estatal de salud, pese a la ampliación que tuvo en el período, como tampoco por la atención que empezaban a ofrecer los sindicatos con sus obras sociales. En su mayoría se trataba de inmigrantes gallegos o peninsulares de primera y segunda generación que, si no eligieron esta mutual por su identidad étnica, una vez asociados pudieron encontrar en la simbología del centro una forma de crear o recrear esa identificación - desde la cruz de Santiago en el carnet y la revista, que mensualmente recibían en sus casas, a la imponente entrada del sanatorio ${ }^{98}$ - . Una realidad alimentada por la oleada migratoria de posguerra ${ }^{99}$, que amerita el análisis de la conjunción que supone la etnicidad, el cuidado de la salud y la organización mutualista en el sistema sanitario argentino aun cuando tanto la sociedad como el sistema hubieran sido objeto de importantes transformaciones.

\section{CONSIDERACIONES FINALES}

Como señalé al comienzo, en este trabajo busqué poner en diálogo la historiografía de las migraciones europeas a la Argentina con la historia de la salud a partir del estudio de una mutual definida por la etnicidad. Aunque ambas dimensiones no pueden escindirse, en atención a las reflexiones que sugiere el análisis cabría diferenciarlas.

atención pública en los hospitales de la ciudad de Buenos Aires, Alberto Dal Bo (2008) señala que si no fuera por los médicos concurrentes (no rentados) a medio día los hospitales quedaban desiertos. El número de profesionales de las instituciones mencionadas figura en el presupuesto provincial de1950. CDDS, 1948-1949 T. IV: 2927-2931. Ley 5364, http://www. gob.gba.gov.ar/intranet/digesto/PDF/05364.pdf

97 Ramaciotti, 2009: 92-93. Ortiz Bergia, 2015.

98 La revista que el centro destinaba a los socios hizo su aparición en 1913 y se editaba mensualmente con un importante tiraje (60 000 ejemplares en los años cuarenta).

99 En 1960 el Centro Gallego tenía 104000 socios, cifra poco mayor que la de 1970. Aún estaba lejos la profunda crisis que atravesó, como el conjunto del sistema sanitario argentino, en los años noventa. Cagiao Vila y Peña Saavedra, 2008: 28. 
Desde la perspectiva del sistema sanitario, por un lado, el crecimiento de una entidad como el Centro Gallego pone de manifiesto la diversidad de situaciones existentes al interior del mutualismo en momentos en que este acusaba la crisis que también afectaba a otros sectores de la salud. El papel que desempeñó en los años treinta y cuarenta del siglo pasado, cuando llegó a tener unos 90000 socios al tiempo que amplió sus instalaciones y servicios a pesar de la expansión de la salud pública en manos del Estado, evidencia la necesidad de tener en cuenta este sector a la hora de evaluar el conjunto del sistema sanitario argentino en el período. La posición relativa de sus prestaciones frente a los hospitales de colectivos migratorios y aún de gestión estatal, el número de médicos y su dedicación horaria, los servicios técnicos y farmacológicos, la calidad de la internación o el mantenimiento de las instalaciones son algunos indicadores del funcionamiento del sanatorio que a la par de dar cuenta de las transformaciones en el área explican la demanda que tuviera.

Así, las limitaciones de los hospitales públicos junto con la accesibilidad de este servicio para los sectores medios o en ascenso, cuyas expectativas sobre el cuidado de la salud habían ido en aumento, convergieron para mantener y aun acrecentar el sistema de previsión que brindaba esta mutual. De la manera idiosincrática con que se conducía el peronismo, así se habría visualizado también desde el Estado, tanto de manera general a través de la creación de la Dirección de Mutualidades, como de forma selectiva mediante subsidios y beneficios otorgados en un intercambio que al parecer podía tener más de una dirección si tenemos en cuenta a la dirigencia y sus relaciones hacia adentro y hacia afuera de la institución. Aunque este caso no puede generalizarse, contrariamente a lo sostenido por la historia de la salud pública, el Centro Gallego llama la atención sobre el papel de las mutuales que daban cauce a esta forma de previsión tanto durante como después del peronismo, sea por el marco institucional generado por el Estado, sea por el sector de la población al que brindaban cobertura en un país donde el proceso de industrialización al que estaban vinculados los gremios y sus obras sociales era significativo aunque también desparejo.

Desde el punto de vista de los estudios migratorios y de la historia social a la que buscan aportar, el Centro Gallego también arroja luz sobre la importancia de la etnicidad en una época y una dimensión que no se ha tenido suficientemente en cuenta. Más allá del período de inmigración masiva, miles de hombres, mujeres y niños de familias gallegas y peninsulares, continuaban apelando a una cobertura sanitaria diferenciada tanto por el origen como por los estándares de la salud pública del período. Desde un ángulo diferente, esta dimensión sugiere la permanencia del pluralismo social y cultural mucho más allá de las primeras décadas del siglo pasado. 
Ahora bien, como se ha señalado, la identidad étnica es más visible a través de la dirigencia. No obstante, junto a ella, la identidad empresarial — si así puede expresarse-, se hace patente no solo por la composición de la mayoría de los más altos directivos, sino también por las múltiples actividades que implicaba la gestión de las prestaciones sanitarias. Si esto fue así en la mutual gallega durante el período indagado y, conjeturamos, bastante después, mucho más debió serlo en la etapa de expansión del mutualismo. Esta línea propone un ángulo para el estudio del liderazgo que complementa y a la vez da mayor complejidad al rol político y/o configurador de colectivos migratorios que tuvieron estas dirigencias.

En suma, el estudio realizado permite apreciar la coexistencia del asociacionismo étnico con los servicios de salud emergentes en los años cuarenta. Las afinidades por origen continuaron operando en favor de una forma de segmentación que no solo estaba configurada por la situación socio-económica o los avances en la atención médica. De este modo, aun cuando la oleada de posguerra apenas estaba comenzando y la nacionalización o integración social tenían un considerable grado de avance, la etnicidad seguía siendo una dimensión significativa, poniendo en evidencia hasta qué punto el estudio de esta forma de asociacionismo continúa ofreciendo posibilidades tanto para el conocimiento de las migraciones como para el de la sociedad argentina en su conjunto.

\section{BIBLIOGRAFÍA}

Andrenacci, Luciano, Falappa, Fernando y Lvovich, Daniel, "Acerca del Estado de Bienestar del Peronismo Clásico (1943-1955)", Julián Bertranou, Juan Manuel Palacio y Gerardo M. Serrano (comps.), El país del no me acuerdo. (Des)memoria institucional e historia de la política social, Buenos Aires, Prometeo, 2004: 83-115.

Baily, Samuel, "Las sociedades de ayuda mutua y el desarrollo de una comunidad italiana en Buenos Aires, 1858-1918", Desarrollo Económico, 21/84 (Buenos Aires, enero-marzo 1982): 485-514.

Belmartino, Susana, La atención médica argentina en el siglo XX. Instituciones y procesos, Buenos Aires, Siglo XXI, 2005.

Belmartino, Susana, Bloch, Carlos, Persello, Ana Virginia y Quiroga, Hugo, Las Instituciones de Salud en la Argentina. Desarrollo y crisis, Buenos Aires, Secretaria de Ciencia y Técnica, Área de Estudios e investigaciones en Ciencias Sociales para la Salud, 1987.

Belmartino, Susana, Bloch, Carlos, Carnino, María Isabel y Persello, Ana Virginia, Fundamentos históricos de la construcción de relaciones de poder en el sector 
salud. Argentina 1940-1960, Buenos Aires, Organización Panamericana de la Salud, Oficina Regional de la Organización mundial de la Salud Representación Argentina, 1991.

Biernat, Carolina y Ramacciotti, Karina Inés, “Dossier: Nación, provincias y municipios en la centralización del sistema sanitario argentino, 1900-1955", Trabajos y Comunicaciones, 44/20 (La Plata, septiembre 2016). http://www.trabajosycomunicaciones.fahce.unlp.edu.ar/article/view/TyCe020/7557.

Bonardi, Laurent, "El Centro Gallego de Buenos Aires durante la década peronista. Un ejemplo de la lucha entre franquismo y antifranquismo en Argentina", Iberoamericana, 6, 21 (Berlín, 2006): 181-187.

Cabrera, M, A. D. Garat y J. Martínez Garda, "Mutualidad. Cuestiones económicas que afectan a las mutualistas. Soluciones prácticas." Boletín del Museo Social Argentino, XXXII/259-60, (Buenos Aires, enero-febrero 1944): 22-30.

Cagiao Vila, Pilar y Peña Saavedra Vicente, Nós mesmos. Asociacionismo galego na emigración - Asociacionismo gallego en la emigración, [Santiago de Compostela], Consello da Cultura Galega, 2008.

Crespo, Edda, "Entre tradiciones, regionalismos y socorros mutuos: El asociacionismo español en la zona del Golfo San Jorge (1910-1959)", Quinto sol, 20/2 (Santa Rosa, 2016): 1-21. http://dx.doi.org/10.19137/qs1134

Da Orden, María Liliana, Inmigración española, familia y movilidad social en la Argentina Moderna. Una mirada desde Mar del Plata, Buenos Aires, Biblos, 2005.

Da Orden, María Liliana, "Estado y salud pública en la provincia de Buenos Aires: proyectos y prácticas durante el peronismo clásico", XII Jornadas de Historia Politica Peronismo y antiperonismo: claves de interpretación, Mar del Plata, 13 y 14 de noviembre de 2014.

Dal Bo, Alberto, Hospitales de Reforma. Crónicas para evitar el olvido, Buenos Aires, Biblos, 2008.

De Cristóforis, Nadia, "El Centro Gallego de Buenos Aires ante la España dividida: tensiones y conflictos en una institución señera de la colectividad", Nadia De Cristóforis (ed.), La inmigración gallega y su experiencia asociativa en Buenos Aires (1910-1965), Buenos Aires, Imago Mundi, 2014: 19-43.

De Cristóforis, Nadia, "El exilio gallego en Buenos Aires y su inserción institucional: un estudio de caso", Épocas - Revista de Historia, 11 (Buenos Aires, 2015): 17-40. http://p3.usal.edu.ar/index.php/epocas/article/view/3412/4238

Devoto, Fernando, "Participación y conflictos en las sociedades italianos de socorros mutuos", Fernando Devoto y Rosoli Gianfausto (comps.), La inmigración italiana en la Argentina, Buenos Aires, Biblos, 1985: 141-164.

Devoto, Fernando, Historia de la inmigración en la Argentina, Buenos Aires, Sudamericana, 2002. 
Devoto, Fernando y Fernández, Alejandro, "Mutualismo étnico, liderazgo y participación política. Algunas hipótesis de trabajo", Diego Armus (comp.), Mundo urbano y cultura popular. Estudios de Historia Social Argentina, Buenos Aires, Sudamericana, 1990: 128-152.

Díaz, Hernán, Historia de la Federación de Sociedades Gallegas. Identidades políticas y prácticas militantes, Buenos Aires, Biblos, 2007.

Díaz, Hernán, "Instituciones de la colectividad gallega y redes culturales (19401960)", Fernando Devoto y Ramón Villares (comps.), Luis Seoane. Entre Galicia y la Argentina, Buenos Aires, Biblos, 2012: 121-132.

Díaz-R. Labajo, M. Aránzazu, El exilio científico republicano en Argentina. Contribuciones e impacto de los médicos, biomédicos y psicoanalistas españoles en la ciencia argentina (1936-2003), Salamanca, Ediciones Universidad de Salamanca, 2016.

Farías Iglesias, Ruy G., La inmigración gallega en el sur del Gran Buenos Aires, 1869-1960, Tesis Doctoral, Universidade de Santiago de Compostela, Facultade de Xeografía e Historia, Departamento de Historia Contemporánea e de América, 2010. https://minerva.usc.es/xmlui/bitstream/handle/10347/2784/9788498873559_ content.pdf? sequence $=1$

Fernández, Alejandro, "El mutualismo español en Buenos Aires, 1890-1920. Un estudio de caso", Cuadernos de Historia Regional, III/8 (Luján, 1987): 36-71.

Fernández, Alejandro, "Los gallegos dentro de la colectividad y las asociaciones españolas en el primer tercio del siglo XX”, Xosé Manoel Núñez Seixas (ed.), La Galicia Austral, Buenos Aires, Biblos, 2001: 139-160.

Fernández Santiago, Marcelino, "Asociacionismo gallego en Buenos Aires (19361960)", Xosé Manoel Núñez Seixas (ed.), La Galicia Austral, Buenos Aires, Biblos, 2001: 181-201.

Fernández Santiago, Marcelino, "Asociacionismo gallego en América (1861-1960)", Juan Andrés Blanco Rodríguez, El asociacionismo en la emigración española a América, Salamanca, UNED Zamora, 2008: 199-233.

Gerchunoff, Pablo y Antúnez, Damián, "De la bonanza peronista a la crisis de desarrollo", Juan Carlos Torre (dir.), Los años peronistas (1943-1955). Nueva Historia Argentina, Vol. IV, Buenos Aires, Sudamericana, 2002: 125-205.

González Bernaldo de Quirós, Pilar, "El «momento mutualista» en la formulación de un sistema de protección social en Argentina: socorro mutuo y prevención subsidiada a comienzos del siglo XX", Revista de Indias, $73 / 257$ (Madrid, 2013): 157192. https://doi.org/10.3989/revindias.2013.007

Gutiérrez Forte, Javiher "La salud en las sociedades regionales españolas: el caso de La Benéfica", Novas achegas ao estudo da cultura galega II, Coruña, Universidade da Coruña, 2012: 375-380. 
Jankilevich, Ángel, El sector privado como actor social: aportes a las acciones de atención de la salud, Buenos Aires, Leviatán, 2017. http://www.argsaludcomunidad.com.ar/images/El_Sector_Privado_Web.pdf

Lequerica Ibarrola, Ramón, "Información social. Censo de mutualidades correspondiente a su estado actual en 1926", Revista de Ciencias Económicas, XVI/80-8 (Buenos Aires, marzo-abril 1928): 1779-1793.

Mauro, Diego, "El mutualismo católico en Argentina: el Círculo de obreros de Rosario en la primera mitad del siglo XX", Historia Crítica, 55 (Bogotá, enero-marzo 2015): 181-205. https://revistas.uniandes.edu.co/doi/pdf/10.7440/histcrit55.2015.08

Moya, José C., Primos y extranjeros. La inmigración española en Buenos Aires, 1850-1930, Buenos Aires, Emecé, 2004.

Núñez Seixas, Xosé Manoel, "Redes sociales y asociacionismo: las "parroquias" gallegas de Buenos Aires (1904-1936)", Estudios Interdisciplinarios de América Latina y el Caribe, 11/1 (Tel Aviv, 2000): 23-44. http://www7.tau.ac.il/ojs/index. $\mathrm{php} / \mathrm{eial} / \mathrm{article} / \mathrm{view} / 994 / 1029$

Núñez Seixas, Xosé Manoel, "Modelos de liderazgo en comunidades emigradas Algunas reflexiones a partir de los españoles en América (1870-1940)", Alicia Bernasconi y Carina Frid (eds.), De Europa a las Américas. Dirigentes y liderazgos (1880-1960), Buenos Aires, Biblos, 2006: 17-41.

Ortiz Bergia, María José, “La temprana descentralización de los servicios de salud en la Argentina: la construcción del sistema sanitario en Córdoba, 1930-1955", História, Ciências, Saúde - Manguinhos, 22/2 (Río de Janeiro, abril-junio 2015): 559575. http://www.scielo.br/pdf/hcsm/v22n2/0104-5970-hcsm-2015005000005.pdf

Ramaciotti, Karina, La política sanitaria del peronismo, Buenos Aires, Biblos, 2009.

Ross, Peter, "Justicia social: Una evaluación de los logros del peronismo clásico", Anuario IEHS, 8 (Tandil, 1993): 105-124.

Torrado, Susana, Estructura social de la Argentina 1945-1983, Buenos Aires, Ediciones de la Flor, 1992.

Zuloaga, N. G. y González Bollo, H. (coords.), 125 años de la Estadística Porteña. 1887-2012, Buenos Aires, Gobierno de la Ciudad Autónoma de Buenos Aires, Dirección General de Estadística y Censos, 2015.

Fecha de recepción: 26 de marzo de 2018.

Fecha de envío de las modificaciones: 1 de abril de 2019.

Fecha de aceptación: 10 de abril de 2019. 


\section{Health, immigration and mutual aid organization in Argentina: The Centro Gallego of Buenos Aires between the crisis and the emergence of a new health system (1930-1950)}

This article sets up a dialogue between the historiography of the European migrations to Argentina and the field of the history of health through the case study of the Centro Gallego in Buenos Aires, Argentina's most important foreign mutual aid society since the 1930s. Using quantitative and qualitative sources from public and private archives, the article analyses the nature of the health services provided by the institution, the management role of its leaders, as well as the make-up of its members and their health demands. The results lead us to reconsider the role of mutual organizations during the expansion of the public health system, as well as the role of ethnicity among the urban middle and working classes, long after the period of mass immigration.

KeY WORDS: mutual aid; health; Galician migration; Spanish migration; Argentina; twentieth century. 